\title{
Culprit lesion characteristics in very young patients with acute coronary syndrome: An optical coherence tomography study
}

\author{
Sharad Chandra (D, Snigdha Boddu (D, Gaurav Chaudhary (D), Akhil Sharma (D, Akshyaya Pradhan (D), \\ Monika Bhandari (D), Pravesh Vishwakarma (D, Rishi Sethi (D), Varun Shankar Narain (D), Sudhanshu Kumar Dwivedi (D)
}

Department of Cardiology, King George’s Medical University; Uttar Pradesh-India

\section{ABSTRACT}

Objective: The concept of managing patients on the basis of culprit lesion characteristics is emerging. Atherosclerotic plaques are reported to be rare in young patients presenting with acute coronary syndrome (ACS). We aimed to assess culprit lesion characteristics in very young patients presenting with ACS by optical coherence tomography (OCT).

Methods: This was a prospective, single-center, open-label, observational study. Patients aged 35 years or less with ACS who underwent invasive coronary angiography and OCT were studied.

Results: Of the 43 patients, $22(51.2 \%)$ had plaque rupture, $16(37.2 \%)$ had plaque erosion, and five (11.6\%) had no specific lesion character. Plaque was fibroatheromatous in $34(79.1 \%)$ patients and fibrous in seven (16.3\%). Plaque was not found in two $(4.7 \%)$ patients; of these, one $(2.3 \%)$ had left anterior descending coronary artery bridging, and one $(2.3 \%)$ had intimal dissection without any plaque. Plaque rupture was more commonly associated with fibroatheromatous plaques, whereas plaque erosion was more commonly associated with fibrous plaque ( $\mathrm{p}=0.010)$.

Conclusion: Although plaque rupture and plaque erosion occurred at the same rate as seen in patients of all ages, calcified nodule as a culprit lesion was not found in young patients. Majority of the patients had plaque rupture and plaque erosion with fibroatheromatous plaque, signifying the occurrence of established coronary artery disease in very young patients of Southeast Asia.

Keywords: acute coronary syndrome, atherosclerotic plaque, myocardial infarction, optical coherence tomography, ST elevation myocardial infarction

Cite this article as: Chandra S, Boddu S, Chaudhary G, Sharma A, Pradhan A, Bhandari M, et al. Culprit lesion characteristics in very young patients with acute coronary syndrome: An optical coherence tomography study. Anatol J Cardiol 2021; 25: 684-90.

\section{Introduction}

Atherosclerosis is the most common underlying pathology in acute coronary syndrome (ACS) (1). Plaque rupture, the major mechanism for ACS, activates platelets and triggers the coagulation cascade leading to thrombosis which can potentially lead to ACS (2). Autopsy examinations have revealed the absence of plaque disruptions in $25 \%$ patients with ACS (3-6). This is suggestive of additional mechanisms leading to ACS, which include plaque erosions and calcified nodules (7). Differentiation of underlying mechanisms in ACS, namely plaque rupture, plaque erosion, and calcified nodule is not possible with coronary angi- ography owing to its inability to assess vessel wall pathology; and therefore, many patients undergo stent implantation irrespective of the underlying mechanism (8). This "one size fits all" strategy prevents exploration of the natural history of patients with different culprit lesions (4). Optical coherence tomography (OCT) overcomes this shortcoming (8-10).

OCT imaging of culprit coronary arteries in patients with ACS has been performed in a number of studies, and the results of plaque erosion and plaque rupture correlate with autopsy series $(10,11)$. Plaque rupture is associated with larger infarcts with large plaque burden, occluded culprit arteries, larger lipid burden, and larger thrombus burden with predominant red throm- 


\section{HIGHLIGHTS}

- In the very young South Asian population, the mechanism of acute coronary syndrome (ACS) is not yet completely understood.

- In our study, culprit lesion characteristics in patients with ACS below 35 years of age showed that fibroatheromatous plaque was found in most of our patients $(79.1 \%)$, and plaque erosion occurred in more than onethird $(37.2 \%)$ of the study population, signifying the occurrence of established coronary artery disease in very young patients of the South Asia region.

bus. However, plaque erosion is associated with patent culprit arteries, lower lipid burden, and lower thrombus burden with predominantly white thrombus. Plaque erosion is more common in women and young patients (5). Furthermore, plaque erosion may be managed conservatively, whereas plaque rupture necessitates stent implantation $(12,13)$. Plaque erosion managed with thrombosuction and antiplatelet therapy alone demonstrated no clinical recurrences in $12(39 \%)$ lesions at a median follow-up of two years (10). There is evidence for a similar response to intervention in both plaque rupture and erosion (13). Because of discrepancies in the aforementioned studies, large trials to address this issue are warranted. It remains unestablished if ACS with plaque erosion can be managed by alternate means and stenting can be deferred to reduce complications that are secondary to high thrombus burden (14). In this study, we have described culprit lesion characteristics in very young patients $(15,16)$ presenting with ACS by OCT.

\section{Methods}

\section{Study design and patient population}

This was a prospective, single-center, open-label, and observational study conducted at a tertiary-care center in India. Patients aged 35 years or less in whom ACS was a triggered event were studied. All the patients underwent invasive coronary angiography, followed by OCT. The identification of the culprit lesion was made on the basis of coronary angiography, electrocardiography, or echocardiography. Tight lesions that prevented blood clearance by contrast were pre-dilated for good OCT image quality. Patients with heart failure (left ventricular ejection fraction $\leq 30 \%$ ), cardiogenic shock, refractory ventricular arrhythmia requiring pharmacologic or defibrillator therapy, renal failure (serum creatinine $\geq 1.5 \mathrm{mg} / \mathrm{dL}$ ), or ACS with culprit lesion in a bypass graft were excluded from the study. The study inclusion and exclusion criteria are illustrated in Figure 1. The study was performed in accordance with the Declaration of Helsinki, and the study protocol was approved by the Institutional Ethics Committee. Written informed consent was provided by all the enrolled patients after the procedure was explained.

\section{Procedure}

Most of the patients with ST-segment elevation myocardial infarction (STEMI) were taken at an average of six hours after thrombolysis and were stable. Patients with non-STEMI (NSTEMI) were also relatively stable as they did not experience ongoing angina. OCT imaging took approximately 10-15 minutes and in most patients, procedure time was around 40 minutes, including OCT imaging.

\section{Atherosclerotic lesion morphology}

Lesion and reference segments were defined according to the International Working Group for Intravascular OCT Standardization and Validation (IWG-IVOCT) (17).

\section{OCT image acquisition}

The OCT images were acquired with a frequency-domain OCT system and the DragonFly catheter (Ilumien Optis, St. Jude Medical, St. Paul, Minnesota, USA). The automated pullback was performed at a speed of $20 \mathrm{~mm} / \mathrm{s}$ to clear blood from the culprit artery by contrast injection.

Plaque rupture was defined as the presence of rupture or discontinuity in the fibrous cap. Plaque erosion was defined as the presence of an intact fibrous cap with attached thrombus, irregularity of the lumen of the culprit lesion in the absence of thrombus, or lesions with underlying plaque attenuated by thrombus. Lesions such as bridging in the left anterior descending coronary artery or intimal dissection, which did not meet any of the above criteria were categorized as others. Tissue characteristics of underlying plaque were also studied. Fibrous plaque was identified as a homogeneous plaque with high backscatter. Fibroatheromatous plaque was identified as low backscatter plaque with diffuse border and attenuation. Thin-cap fibroatheroma (TCFA) was defined as plaque with lipid content with the thinnest part of the fibrous cap measuring $<65 \mu \mathrm{m}$. Red thrombus was identified by high backscatter and high attenuation. White thrombus was identified by high backscatter with low attenuation. Micro channels were defined as poor signal regions that were sharply delineated in multiple contiguous frames.

\section{Statistical analysis}

The Statistical Package for Social Sciences (SPSS; Chicago, IL, USA) program, version 26 was used for data analysis. Continuous variables were expressed as mean \pm standard deviation and categorical variables as percentages. Categorical variables were compared with the chi-squared test or Fisher's exact test. A $p$ value $<0.05$ was considered statistically significant.

\section{Results}

\section{Baseline characteristics}

A total of 43 patients were included in this study. Of them, $18(41.9 \%)$ were aged between 24 and 30 years, and $25(58.1 \%)$ patients were aged between 31 and 36 years. More men $(n=42$; $97.7 \%$ ) than women participated in the study. The most com- 


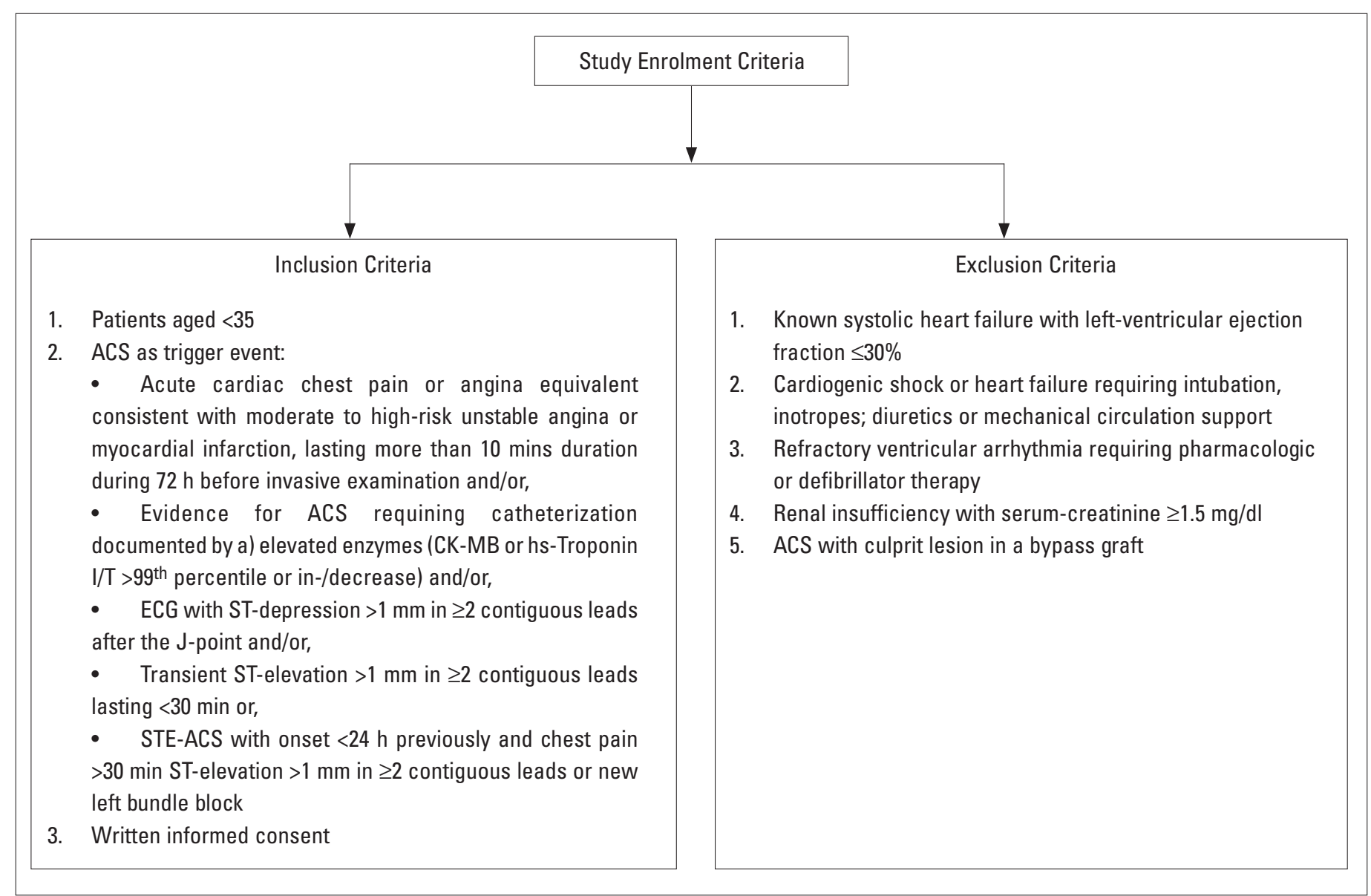

Figure 1. Study inclusion and exclusion criteria

\begin{tabular}{|c|c|}
\hline Characteristics & Patients ( $n=43$ ) \\
\hline \multicolumn{2}{|l|}{ Age } \\
\hline $24-30$ years, $\mathrm{n}(\%)$ & $18(41.9)$ \\
\hline $31-36$ years, $\mathrm{n}(\%)$ & $25(58.1)$ \\
\hline Male, $\mathrm{n}(\%)$ & $42(97.7)$ \\
\hline \multicolumn{2}{|l|}{ Risk factors } \\
\hline Smoker, n (\%) & $23(53.5)$ \\
\hline Tobacco chewing, $\mathrm{n}(\%)$ & $17(39.5)$ \\
\hline Diabetes, n (\%) & $2(4.7)$ \\
\hline Hypertension, n (\%) & $2(4.7)$ \\
\hline Family history of coronary artery disease, $\mathrm{n}(\%)$ & $2(4.7)$ \\
\hline \multicolumn{2}{|l|}{ Diagnosis } \\
\hline ST-segment elevation myocardial infarction, $\mathrm{n}(\%)$ & $31(72.1)$ \\
\hline Non-ST-elevation acute coronary syndrome, n (\%) & $12(27.9)$ \\
\hline Thrombolysis, n (\%) & $21(48.8)$ \\
\hline \multicolumn{2}{|l|}{ Ejection fraction } \\
\hline$<50, \mathrm{n}(\%)$ & $20(46.5)$ \\
\hline$\geq 50, n(\%)$ & $23(53.5)$ \\
\hline
\end{tabular}

mon risk factors were smoking ( $n=23 ; 53.5 \%$ patients), followed by tobacco chewing ( $n=17 ; 39.5 \%$ patients). Most common clinical presentation was STEMI in $31(72.1 \%)$ patients and NSTEMI ACS in $12(27.9 \%)$ patients. The baseline characteristics of the study population are demonstrated in Table 1.

\section{Lesion characteristics}

On coronary angiography, $36(83.7 \%)$ patients displayed single-vessel disease. The culprit artery was left anterior descending coronary artery in $35(81.4 \%)$ patients, right coronary artery in six $(14.0 \%)$, and the left circumflex artery in two $(4.7 \%)$ patients. The coronary culprit lesion was plaque rupture in $22(51.2 \%)$ patients, plaque erosion in $16(37.2 \%)$, and five $(11.6 \%)$ had no specific lesion character. Plaque was not found in two $(4.7 \%)$ patients; of these, one $(2.3 \%)$ had left anterior descending coronary artery bridging, and the other $(2.3 \%)$ had intimal dissection without any plaque. Plaque was fibroatheromatous in $34(79.1 \%)$ patients and fibrous in seven (16.3\%). Thirty-four (79.1\%) patients underwent percutaneous coronary intervention, eight $(18.6 \%)$ were medically managed, and one (2.3\%) underwent thrombosuction alone. Red, red and white, and white thrombi were observed in $12(27.9 \%), 11(25.6 \%)$, and nine $(20.9 \%)$ patients, respectively. The lesion characteristics are elaborated in Table 2. Figures 2 and 3 show OCT images for 


\begin{tabular}{|c|c|}
\hline Characteristics & Patients ( $n=43$ ) \\
\hline \multicolumn{2}{|l|}{ Number of diseased vessels } \\
\hline Single-vessel disease, $\mathrm{n}(\%)$ & $36(83.7)$ \\
\hline Double-vessel disease, $\mathrm{n}(\%)$ & $6(14.0)$ \\
\hline Triple-vessel disease, $\mathrm{n}(\%)$ & $1(2.3)$ \\
\hline \multicolumn{2}{|l|}{ Culprit artery on coronary angiography } \\
\hline Left anterior descending artery, $\mathrm{n}(\%)$ & $35(81.4)$ \\
\hline Right coronary artery, $\mathrm{n}(\%)$ & $6(14.0)$ \\
\hline Left circumflex artery, $\mathrm{n}(\%)$ & $2(4.7)$ \\
\hline \multicolumn{2}{|l|}{ Plaque character } \\
\hline Plaque rupture, n (\%) & $22(51.2)$ \\
\hline Plaque erosion, n (\%) & $16(37.2)$ \\
\hline Others, $\mathrm{n}(\%)$ & $5(11.6)$ \\
\hline \multicolumn{2}{|l|}{ Plaque character } \\
\hline Nil, $\mathrm{n}(\%)$ & $2(4.7)$ \\
\hline Fibroatheroma, n (\%) & $34(79.1)$ \\
\hline Fibrous, $\mathrm{n}(\%)$ & $7(16.3)$ \\
\hline \multicolumn{2}{|l|}{ Management } \\
\hline Medical, n (\%) & $8(18.6)$ \\
\hline Percutaneous coronary intervention, $\mathrm{n}(\%)$ & $34(79.1)$ \\
\hline Thrombosuction, n (\%) & $1(2.3)$ \\
\hline \multicolumn{2}{|l|}{ Thrombus } \\
\hline Nil, n (\%) & $11(25.6)$ \\
\hline Red, n (\%) & $12(27.9)$ \\
\hline Red and white, $\mathrm{n}(\%)$ & $11(25.6)$ \\
\hline White, n (\%) & $9(20.9)$ \\
\hline
\end{tabular}

fibroatheromatous plaque and red thrombus, respectively, in individual patients.

\section{Plaque and thrombus characteristics comparison}

Plaque rupture was more commonly associated with fibroatheromatous plaques, whereas plaque erosion was more commonly associated with fibrous plaque $(p=0.010)$. Plaque rupture and erosion were both more commonly seen in patients with STEMI, although not statistically significant. Plaque rupture was also more commonly associated with thin-cap fibroatheroma, although not statistically significant. The plaque and thrombus character comparison is shown in Table 3.

\section{Lesion characteristics comparison}

The mean minimal lumen area (MLA) was higher in patients with plaque erosion than in those with plaque rupture $(2.64 \pm 1.78$ vs. $2.96 \pm 1.43 \mathrm{~mm}^{2}$ ), and the mean fibrous cap thickness was higher in patients with plaque erosion than in those with plaque rupture $(126.67 \pm 48.22$ vs. $105.71 \pm 48.02 \mu \mathrm{m})$. Lesion length was higher in patients with plaque rupture compared with those with plaque erosion $(20.86 \pm 7.91$ vs. $18.56 \pm 7.59 \mathrm{~mm})$. However, none of these differences were found to be statistically significant. The comparison of lesion characteristics is shown in Table 4.

\section{Lipid profile}

Mean cholesterol was $172.84 \pm 49.66 \mathrm{mg} / \mathrm{dL}$. Mean low-density lipoprotein cholesterol (LDL-C) was $83.21 \pm 40.85 \mathrm{mg} / \mathrm{dL}$, and high-density lipoprotein was $41.65 \pm 9.86 \mathrm{mg} / \mathrm{dL}$. The lipid parameters are detailed in Table 5.

\section{Discussion}

In this study, we aimed to shed light on culprit lesion characteristics in very young patients presenting with ACS by OCT. Of

Table 3. Plaque and thrombus characteristics comparison

\begin{tabular}{|c|c|c|c|c|}
\hline \multirow[b]{2}{*}{ Characteristics } & \multicolumn{3}{|c|}{ OCT findings } & \multirow[b]{2}{*}{$P$-value } \\
\hline & Plaque rupture ( $\mathrm{n}=22$ ) & Plaque erosion $(n=16)$ & Total $(\mathbf{n}=\mathbf{3 8})$ & \\
\hline \multicolumn{5}{|l|}{ Plaque character } \\
\hline Fibroatheroma, n (\%) & $21(95.5)$ & $10(62.5)$ & $31(81.8)$ & 0.010 \\
\hline Fibrous, $n(\%)$ & $1(4.5)$ & $6(37.5)$ & $7(18.4)$ & \\
\hline Thin-cap fibroatheroma, $\mathrm{n}(\%)$ & $7(31.8)$ & $1(6.2)$ & $8(21.1)$ & 0.056 \\
\hline \multicolumn{5}{|l|}{ Thrombus } \\
\hline Nil, $n(\%)$ & $1(4.5)$ & $5(31.2)$ & $6(15.8)$ & 0.050 \\
\hline Red, $n(\%)$ & $8(36.4)$ & $4(25.0)$ & $12(31.6)$ & \\
\hline Red and white, $\mathrm{n}(\%)$ & $9(40.9)$ & $2(12.5)$ & $11(28.9)$ & \\
\hline White, $\mathrm{n}(\%)$ & $4(18.2)$ & $5(31.2)$ & $9(23.7)$ & \\
\hline \multicolumn{5}{|l|}{ Clinical presentation } \\
\hline ST-segment elevation myocardial infarction, $n(\%)$ & $17(77.3)$ & $12(75.0)$ & $29(76.3)$ & 0.871 \\
\hline Non ST-segment elevation myocardial infarction, $\mathrm{n}(\%)$ & $5(22.7)$ & $4(25.0)$ & $9(23.7)$ & \\
\hline
\end{tabular}




\begin{tabular}{|c|c|c|c|c|}
\hline Lesion characteristics & OCT findings & $\mathbf{n}$ & Mean \pm SD & $P$-value \\
\hline $\mathrm{MLA}, \mathrm{mm}^{2}($ mean $\pm \mathrm{SD})$ & Plaque rupture & 22 & $1.96 \pm 1.43$ & 0.201 \\
\hline \multirow[t]{2}{*}{$\mathrm{MSA}, \mathrm{mm}^{2}($ mean $\pm \mathrm{SD})$} & Plaque rupture & 16 & $7.47 \pm 1.79$ & 0.711 \\
\hline & Plaque erosion & 9 & $7.22 \pm 1.06$ & \\
\hline Fibrous cap thickness, $\mu$ m (mean $\pm S D)$ & Plaque erosion & 9 & $126.67 \pm 48.22$ & \\
\hline \multirow[t]{2}{*}{ Length of the lesion, $\mathrm{mm}$ (mean $\pm \mathrm{SD}$ ) } & Plaque rupture & 22 & $20.86 \pm 7.91$ & 0.374 \\
\hline & Plaque erosion & 16 & $18.56 \pm 7.59$ & \\
\hline
\end{tabular}

\begin{tabular}{|lc|}
\hline \multicolumn{2}{|l|}{ Table 5. Lipid parameters } \\
\hline Lipids & Mean \pm SD \\
\hline Cholesterol, mg/dL & $172.84 \pm 49.66$ \\
LDL-C, mg/dL & $83.21 \pm 40.85$ \\
HDL, mg/dL & $41.65 \pm 9.86$ \\
Triglycerides, mg/dL & $158.02 \pm 67.36$ \\
Lipoprotein a, nmol/L & $57.70 \pm 54.49$ \\
Ejection fraction, $\%$ & $49.12 \pm 7.59$ \\
Fibrous cap thickness, $\mu \mathrm{m}$ & $114.06 \pm 48.72$ \\
Intimal thickness, $\mu \mathrm{m}$ & $315.81 \pm 128.16$ \\
MLA, mm² & $2.36 \pm 1.92$ \\
MSA, mm² & $7.42 \pm 1.50$ \\
\hline LDL-C - low-density lipoprotein cholesterol, HDL - high-density lipoprotein, MLA - \\
minimal lumen area, MSA - minimum stent area, SD - standard deviation \\
\hline
\end{tabular}

the 43 patients who underwent OCT imaging, 22 (51.2\%) had plaque rupture, $16(37.2 \%)$ had plaque erosion, and five $(11.6 \%)$ had no specific lesion character.

Numerous autopsy series and imaging studies have been performed to identify the culprit lesion characteristics. Identification of plaque with intact caps (plaque erosion) as culprit lesions has garnered much interest. Many of these studies relied on OCT imaging owing to its superior spatial resolution $(15 \mu \mathrm{m})$ compared with that of IVUS $(100-200 \mu \mathrm{m})(13)$.

Evidence in literature suggests an uncommon occurrence of atherosclerotic plaque or high plaque burden in young patients with ACS. In this study, patients with ACS aged 35 years or less were included, and 41 (95.4\%) have shown plaques as a cause for ACS. Earlier, Russo et al. (18) studied underlying mechanisms of ACS in Caucasian and Asian populations. The study concluded that Asian and Caucasian patients with ACS showed similar underlying mechanisms, except for a higher risk of calcified plaque in the Caucasian population with NSTEMI-ACS.

Table 6 represents plaque characteristics such as plaque rupture, plaque erosion, and calcified nodule observed in this study with that of other studies assessing culprit lesion morphologies causing STEMI using OCT.

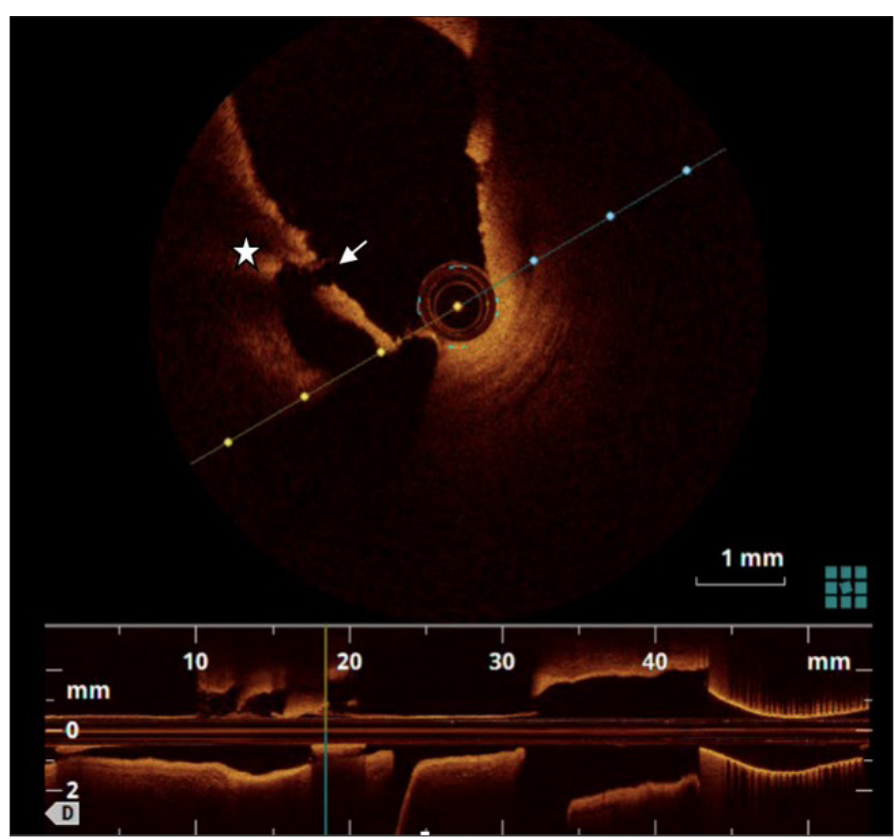

Figure 2. Optical coherence tomography showing fibroatheromatous plaque (star) with plaque rupture (arrow) in a 32-year male who presented with anterior wall myocardial infarction. Angiography showed a $50 \%$ lesion in the proximal left anterior descending coronary artery

Our study included predominantly men $(97.7 \%)$ and did not provide ample samples for women for sex stratification of patients with ACS. Although earlier studies had witnessed significantly higher prevalence of plaque erosion in women of younger age, this finding was not confirmed in the OCTAVIA study (19), which was designed to assess sex differences in the pathophysiology of STEMI. Similarly, Fang et al. (20) have studied culprit lesion morphology in young patients with STEMI and older patients. Culprit lesions in younger patients with STEMI had more plaque erosion $(32.0 \%$ vs. $21.1 \%, \mathrm{p}<0.001)$ and larger minimal lumen area $\left(2.3 \pm 1.7 \mathrm{~mm}^{2}\right.$ vs. $\left.1.9 \pm 1.1 \mathrm{~mm}^{2}, \mathrm{p}<0.001\right)$ than in those in older patients. Similar to these findings, the study by Jia et al. (7) has observed more plaque erosion in younger patients. However, prevalence of these lesions was not greater in women than men. The justification provided for this discrepancy was selection bias as patients of varying clinical presenta- 


\begin{tabular}{|c|c|c|c|c|}
\hline Study & Lesions & $\begin{array}{l}\text { Plaque } \\
\text { rupture }\end{array}$ & $\begin{array}{l}\text { Plaque } \\
\text { erosion }\end{array}$ & $\begin{array}{c}\text { Calcified } \\
\text { nodule }\end{array}$ \\
\hline Wang et al. (22) & 64 & $57.8 \%$ & $39.0 \%$ & $3.1 \%$ \\
\hline Kajander et al. (24) & 70 & $48.6 \%$ & $44.3 \%$ & $7.1 \%$ \\
\hline Saia et al. (21) & 97 & $64.9 \%$ & $33.0 \%$ & - \\
\hline Higuma et al. (23) & 112 & $64.3 \%$ & $26.8 \%$ & $8.0 \%$ \\
\hline Jia et al. (7) & 126 & $43.7 \%$ & $31.0 \%$ & $7.9 \%$ \\
\hline Hu et al. (25) & 141 & $56.0 \%$ & $44.0 \%$ & - \\
\hline This study & 43 & $51.2 \%$ & $37.2 \%$ & - \\
\hline
\end{tabular}

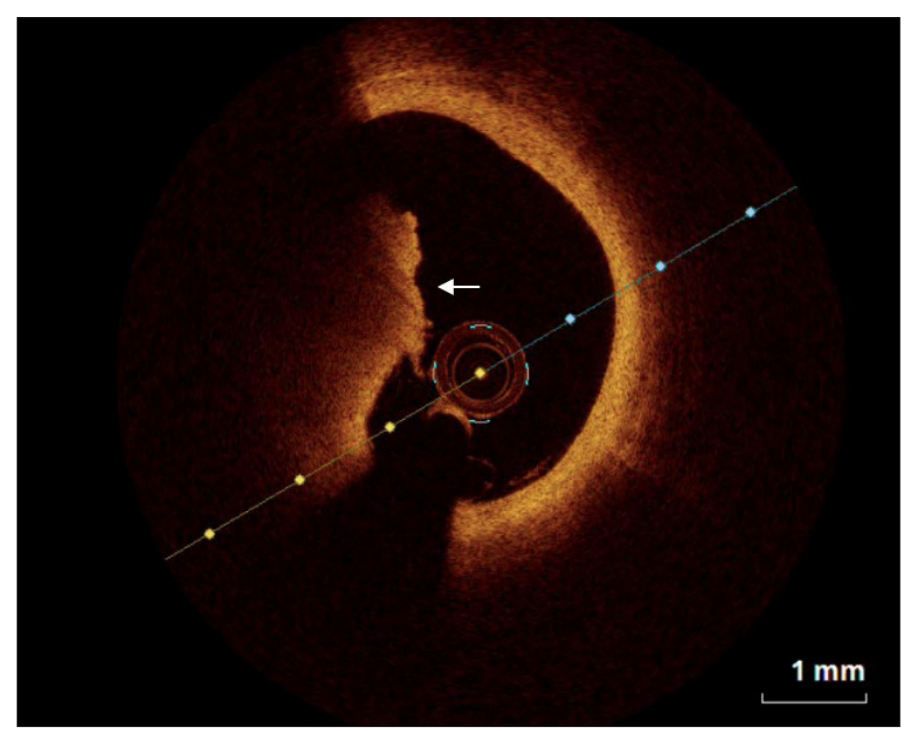

Figure 3. Optical coherence tomography showing a red thrombus (arrow) in a 36-year male who presented with anterior wall myocardial infarction. Angiography showed $70 \%$ lesion in the proximal left anterior descending coronary artery

tion, age, history, and thrombotic state were included in the various studies.

Other plaque characteristics observed in our study correlate with the previous studies. Plaque erosion had more fibrous plaque and less thin-cap fibroatheroma (21-23). Plaque erosion had a thicker fibrous cap $(7,21,23)$. However, plaque rupture had greater lesion length $(7,23)$.

The assessment of culprit lesion morphology in young patients might throw a light on the etiopathogenesis of ACS in this age group compared with that in older patients. Knowledge of the etiopathogenesis of ACS may help in its prevention. Further studies are required to see if treatment strategies differ based on culprit lesion characteristics.

\section{Study limitations}

There were a few limitations to this study. The sample size was small as due to the single center design and only young patients were eligible for enrollment. However, this is the first study to classify the underlying plaque characteristics of very young patients with ACS exclusively. Second, the presence of red thrombus in the culprit lesion showed significant attenuation, which might have reduced the ability to study the characteristics of the plaque underneath it. Another limitation was that a few tight lesions were pre-dilated to allow sufficient blood clearance to ensure good quality images. This pre-dilation caused plaque rupture in a few patients and might have falsely increased the number of plaque rupture lesions.

\section{Conclusion}

This study exclusively included patients with ACS below 35 years of age, whose culprit lesion characters were studied. Although plaque rupture and plaque erosion occurred at the same rate as seen in patients of all age groups, calcified nodule as a culprit lesion was not found in very young patients. This study proves that plaque erosion occurs in a significant number of very young patients presenting with ACS. Further studies are required to identify if this subset benefits from conservative management rather than stent implantation.

\section{Conflict of interest: None declared.}

Peer-review: Externally peer-reviewed.

Author contributions: Concept - S.C., S.B., G.C.; Design - S.C., S.B., G.C.; Supervision - S.C., S.B., G.C., A.S., A.P., M.B., P.V., R.S., V.S.N., S.K.D.; Fundings - None; Materials - S.C., S.B., G.C., A.S., A.P., M.B., P.V., R.S., V.S.N., S.K.D.; Data collection \&/or processing - S.C., S.B., G.C., A.S., A.P., M.B., P.V., R.S., V.S.N., S.K.D.; Analysis \&/or interpretation - S.C., S.B., G.C., A.S., A.P., M.B., P.V., R.S., V.S.N., S.K.D.; Literature search - S.C., G.C.; Writing - S.C., G.C.; Critical review - S.C., S.B., G.C., A.S., A.P., M.B., P.V., R.S., V.S.N., S.K.D.

\section{References}

1. Davies MJ. The pathophysiology of acute coronary syndromes. Heart 2000; 83: 361-6. [Crossref]

2. Davies MJ, Thomas AC. Plaque fissuring--the cause of acute myocardial infarction, sudden ischaemic death, and crescendo angina. Br Heart J 1985; 53: 363-73. [Crossref]

3. Arbustini E, Dal Bello B, Morbini P, Burke A, Bocciarelli M, Specchia $G$, et al. Plaque erosion is a major substrate for coronary thrombosis in acute myocardial infarction. Heart 1999; 82: 269-72. [Crossref]

4. Falk E, Nakano M, Bentzon JF, Finn AV, Virmani R. Update on acute coronary syndromes: the pathologists' view. Eur Heart J 2013; 34: 719-28. [Crossref]

5. Farb A, Burke AP, Tang AL, Liang Y, Mannan P, Smialek J, et al. Coronary plaque erosion without rupture into a lipid core: A frequent cause of coronary thrombosis in sudden coronary death. Circulation 1996; 93: 1354-63. [Crossref]

6. Naghavi M, Libby P, Falk E, Casscells SW, Litovsky S, Rumberger J, et al. From vulnerable plaque to vulnerable patient: a call for new definitions and risk assessment strategies: Part I. Circulation 2003; 108: 1664-72. [Crossref]

7. Jia $H$, Abtahian $F$, Aguirre $A D$, Lee $S$, Chia $S$, Lowe $H$, et al. In vivo diagnosis of plaque erosion and calcified nodule in patients with 
acute coronary syndrome by intravascular optical coherence tomography. J Am Coll Cardiol 2013; 62: 1748-58. [Crossref]

8. Holmes DR Jr, Lerman A, Moreno PR, King SB 3rd, Sharma SK. Diagnosis and management of STEMI arising from plaque erosion. JACC Cardiovasc Imaging 2013; 6: 290-6. [Crossref]

9. Braunwald E. Coronary plaque erosion: Recognition and management. JACC Cardiovasc Imaging 2013; 6: 288-9. [Crossref]

10. Prati F, Uemura S, Souteyrand G, Virmani R, Motreff P, Di Vito L, et al. OCT-based diagnosis and management of STEMI associated with intact fibrous cap. JACC Cardiovasc Imaging 2013; 6: 283-7. [Crossref]

11. Prati F, Regar E, Mintz GS, Arbustini E, Di Mario C, Jang IK, et al.; Expert's OCT Review Document. Expert review document on methodology, terminology, and clinical applications of optical coherence tomography: physical principles, methodology of image acquisition, and clinical application for assessment of coronary arteries and atherosclerosis. Eur Heart $\mathrm{J} 2010$; 31: 401-15. [Crossref]

12. Burke AP, Farb A, Malcom GT, Liang Y-h, Smialek J, Virmani R. Effect of risk factors on the mechanism of acute thrombosis and sudden coronary death in women. Circulation 1998; 97: 2110-6. [Crossref]

13. Ozaki Y, Okumura M, Ismail TF, Motoyama S, Naruse H, Hattori K, et al. Coronary CT angiographic characteristics of culprit lesions in acute coronary syndromes not related to plaque rupture as defined by optical coherence tomography and angioscopy. Eur Heart J 2011; 32: 2814-23. [Crossref]

14. Carrick D, Oldroyd KG, McEntegart M, Haig C, Petrie MC, Eteiba H, et al. A randomized trial of deferred stenting versus immediate stenting to prevent no-or slow-reflow in acute ST-segment elevation myocardial infarction (DEFER-STEMI). J Am Coll Cardiol 2014; 63: 2088-98. [Crossref]

15. Aggarwal A, Srivastava S, Velmurugan M. Newer perspectives of coronary artery disease in young. World J Cardiol 2016; 8: 728-34. [Crossref]

16. Christus T, Shukkur AM, Rashdan I, Koshy T, Alanbaei M, Zubaid M, et al. Coronary Artery Disease in Patients Aged 35 or less - A Different Beast? Heart Views 2011; 12: 7-11. [Crossref]

17. Tearney GJ, Regar E, Akasaka T, Adriaenssens T, Barlis P, Bezerra $\mathrm{HG}$, et al. Consensus standards for acquisition, measurement, and reporting of intravascular optical coherence tomography studies: $A$ report from the International Working Group for Intravascular Optical Coherence Tomography Standardization and Validation. J Am Coll Cardiol 2012; 59: 1058-72. [Crossref]

18. Russo M, Kim HO, Thondapu V, Kurihara O, Araki M, Shinohara H, et al. Ethnic differences in the pathobiology of acute coronary syndromes between Asians and Whites. Am J Cardiol 2020; 125: 1757-64. [Crossref]

19. Guagliumi G, Capodanno D, Saia F, Musumeci G, Tarantini G, Garbo $\mathrm{R}$, et al. Mechanisms of atherothrombosis and vascular response to primary percutaneous coronary intervention in women versus men with acute myocardial infarction: Results of the OCTAVIA study. JACC Cardiovasc Interv 2014; 7: 958-68. [Crossref]

20. Fang C, Dai J, Zhang S, Wang Y, Wang J, Li L, et al. Culprit lesion morphology in young patients with ST-segment elevated myocardial infarction: A clinical, angiographic and optical coherence tomography study. Atherosclerosis 2019; 289: 94-100. [Crossref]

21. Saia F, Komukai K, Capodanno D, Sirbu V, Musumeci G, Boccuzzi G, et al. Eroded versus ruptured plaques at the culprit site of STEMI: In vivo pathophysiological features and response to primary $\mathrm{PCl}$. JACC Cardiovasc Imaging 2015; 8: 566-75. [Crossref]

22. Wang L, Parodi G, Maehara A, Valenti R, Migliorini A, Vergara R, et al. Variable underlying morphology of culprit plaques associated with ST-elevation myocardial infarction: an optical coherence tomography analysis from the SMART trial. Eur Heart J Cardiovasc Imaging 2015; 16: 1381-9. [Crossref]

23. Higuma T, Soeda T, Abe N, Yamada M, Yokoyama H, Shibutani S, et al. A combined optical coherence tomography and intravascular ultrasound study on plaque rupture, plaque erosion, and calcified nodule in patients with ST-segment elevation myocardial infarction: Incidence, morphologic characteristics, and outcomes after percutaneous coronary intervention. JACC Cardiovasc Interv 2015; 8: 1166-76. [Crossref]

24. Kajander OA, Pinilla-Echeverri N, Jolly SS, Bhindi R, Huhtala $H$, Niemelä K, et al. Culprit plaque morphology in STEMI-an optical coherence tomography study: Insights from the TOTAL-OCT substudy. Eurolntervention 2016; 12: 716-23. [Crossref]

25. Hu S, Zhu Y, Zhang Y, Dai J, Li L, Dauerman H, et al. Management and outcome of patients with acute coronary syndrome caused by plaque rupture versus plaque erosion: An intravascular optical coherence tomography study. J Am Heart Assoc 2017; 6: e004730. [Crossref] 